\title{
Risk Assessment of Ferris wheel Trusses Based on FMECA-Fuzzy Evaluation Method
}

\author{
Xiang-dong $\mathrm{Li}^{1}$,Min-yao Huang ${ }^{2}$,Xin-dong Zhang ${ }^{1}$,Wei Zhang ${ }^{1}$, \\ Su-qian Lian $^{2}$ and Zhi-rong Wang ${ }^{2, *}$ \\ ${ }^{1}$ Jiangsu Province Special Equipment Safety Supervision Inspection Institute, Nanjing210036, \\ Jiangsu, China. \\ ${ }^{2}$ College of Safety Science and Engineering, Nanjing Tech University, Nanjing 210009, Jiangsu, \\ China. \\ wangzhirong@njtech.edu.cn \\ ${ }^{*}$ Corresponding author
}

Keywords: Truss, Ferris Wheel, Failure Modes, Fuzzy Evaluation, Risk Level.

\begin{abstract}
The truss is a key part of a Ferris wheel system and affects the safety of the entire Ferris wheel system directly. This paper proposes an analytical method based on failure modes, effects, and criticality analysis (FMECA) and a fuzzy evaluation method for evaluating the risk level of the trusses of the Ferris wheel system; the analytical method includes qualitatively analyzing the operation, failure modes, failure cause, failure rate, and severity through FMECA and quantitatively assessing the safety by using the fuzzy evaluation method. A case study is presented to demonstrate the effectiveness, reliability, and practicability of the analytical method in assessing the risk level of the Ferris wheel trusses. The results show that the highest risk of the failure mode is truss fracture and that the truss itself has a lower level of risk. The results coincided with the real test.
\end{abstract}

\section{Introduction}

Ferris wheel is one of the most important amusement equipments in the playground and it represents the size and sophistication of a play ground. Visitors ride the Ferris wheel to see the scenery with the wheel rotates slowly and continuously. A Ferris wheel always consists of a wheel, driving devices, columns, and a control room. The trusses are the most popular form of the wheel. They extend from the main shaft and then the outer trusses forming the large wheel; thus, the trusses require strict quality control and assurance.

The traditional FMECA evaluation results were expressed qualitatively and have thus used for presenting abstract descriptions. Furthermore, the safety of Ferris wheel trusses has not been evaluated. In the present study, the FMECA and the fuzzy evaluation method were combined to assess the risk level of Ferris wheel trusses. The proposed method may provide a reference for future research on the safety of large recreational facilities.

\section{FMECA}

FMECA consists of two parts: Failure modes and effects analysis (FMEA) and criticality analysis (CA)[1].

FMEA. Essentially, FMEA is a qualitative analysis method that involves a hardware method, function method, and mixed method. The hardware method is a bottom-up failure analysis method that can be used to analyze failure modes, failure causes, and effects of each component on the basis of design drawings[2]. The function method is also an up-bottom failure analysis method for analyzing each function of products without the use of design drawings. The mixed method is a combination of the hardware and function method and is used to assess function failure and component failure in complex systems.

CA. The CA method involves a criticality matrix and risk priority number (RPN). The RPN is a qualitative analysis method in which the failure probability and severity of equipment failures are 
scored by relevant experts and designers. In theory, the RPN is the product of occurrence probability ranking $(\mathrm{OPR})$ and effect severity ranking $(\mathrm{ESR})$ : $\mathrm{RPN}=\mathrm{OPR} \times \mathrm{ESR}$. By default, the highest probability of occurrence and the maximum degree of severity will be scored as 10 . Once every unit of a system has been assigned an RPN value, compensation measures should be implemented for the units, from the highest to the lowest RPN value. The compensation measures serve to alleviate high-risk failure modes[3]. The probability level of general faults and the severity of general faults are listed in Tables 1 and 2 .

Table 1. Probability levelof general faults

\begin{tabular}{lll}
\hline Ranking & Occurrence Probability & Scores \\
\hline A & Very high & 9,10 \\
B & High & 7,8 \\
C & Moderate & 5,6 \\
D & Low & 3,4 \\
E & Very low & 1,2 \\
\hline
\end{tabular}

Table 2.Severity of general faults

\begin{tabular}{lll}
\hline Ranking & Effect Severity & Scores \\
\hline I & Fatal effect, loss of function, and death & 9,10 \\
II & $\begin{array}{l}\text { Appreciable effect, loss of function, } \\
\text { and injury }\end{array}$ & 7,8 \\
III & $\begin{array}{l}\text { Greater impact, partial loss of function, } \\
\text { and injury }\end{array}$ & 5,6 \\
IV & Slight influence, minor injury & 3,4 \\
V & Minimal impact & 1,2 \\
\hline
\end{tabular}

\section{Fuzzy Evaluation Method}

The fuzzy evaluation method is an effective comprehensive evaluation method for assessing various factors of a system; the method is based on fuzzy mathematical theory [4].This method can transform a qualitative evaluation into a quantitative evaluation.

Determination of Weight. In this study, the analytic hierarchy process (AHP) was used to determine the weight of an index. The AHP is a multi objective and multi criteria decision-making evaluation method, and it can be used to dismantle complex systems in to small modules to render a complex problem tractable [5]. It combines quantitative analysis and qualitative analysis.

The method for judging the relative importance value and the significance of the 1-9scale are presented in Table 3.

Table 3.Significance of the scale

\begin{tabular}{ll}
\hline Scales & Meaning \\
\hline 1 & The two factors are equally critical \\
3 & The former factor is slightly more critical than the latter factor \\
5 & The former factor is obviously more critical than the latter factor \\
7 & The former factor is a lot more critical than the latter factor \\
9 & The former factor is substantially more critical than the latter factor \\
$2,4,6,8$ & Intermediate values of the scales \\
Reciprocal & If $\frac{u_{i}}{u_{j}}=u_{i j}$, then $\frac{u_{j}}{u_{i}}=\frac{1}{u_{i j}}$ \\
\hline
\end{tabular}

The judgment is defined as 


$$
B=\left(\begin{array}{cccc}
u_{11} & u_{12} & \cdots & u_{1 n} \\
u_{21} & u_{22} & \cdots & u_{2 n} \\
\vdots & \vdots & \vdots & \vdots \\
u_{n 1} & u_{n 2} & \cdots & u_{n n}
\end{array}\right)
$$

The variables $\lambda_{\max }$ and $\mathrm{w}$ are derived from the expression $\mathrm{Bw}=\lambda_{\max } \mathrm{w}$, and the feature vector is subsequently normalized.

The consistency index (CI) facilitates judging the extent to which decisions break the transitivity rule, and it is defined as

$$
\mathrm{CI}=\frac{\lambda_{\max }-\mathrm{n}}{\mathrm{n}-1}
$$

The consistency ratio (CR) is useful for verifying the consistency of the judgment matrix. When $\mathrm{CR} \leq 0.1$, the comparison matrix meets the requirements. If the comparison matrix does not meet the requirements, the matrix should be further adjusted. The values of the random index (RI) are presented in Table 4.

\begin{tabular}{|c|c|c|c|c|c|c|c|c|c|c|}
\hline Scale & 1 & 2 & 3 & 4 & 5 & 6 & 7 & 8 & 9 & 10 \\
\hline RI & 0.00 & 0.00 & 0.52 & 0.89 & 1.12 & 1.26 & 1.36 & 1.41 & 1.46 & 1.49 \\
\hline
\end{tabular}

Table4. Values of the RI

Determination of the Membership Matrix. The process of determining the membership matrix consists of the following steps:

The component system was divided into three levels and failure mode sets were established. The first-level failure mode sets are given by

$$
A=\left\{A_{1}, A_{2}, \ldots, A_{n}\right\}
$$

wheren denotes the number of second-level failure modes.

The second-level failure mode sets are assumed to be

$$
A_{i}=\left\{A_{i 1}, A_{i 2}, \ldots, A_{i j}\right\}
$$

Where $\mathrm{j}$ denotes the number of third-level failure modes belonging to the second index, and

$$
\mathrm{i}=1,2, \ldots, \mathrm{n} \text {. }
$$

If numerous experts are employed as judges to establish the criterion and grade for each failure mode, the evaluation grade sets $\mathrm{V}$ can be assumed to be given by

$$
\mathrm{V}=\left\{\mathrm{v}_{1}, \mathrm{v}_{2}, \cdots \mathrm{v}_{\mathrm{m}}\right\}
$$

Where $\mathrm{m}$ is the number of evaluation grades for the vth indicator.

On the basis of the failure modes and evaluation criteria, the membership matrix of the failure modes can be expressed as

$$
\left(R_{i}\right)_{j \times m}=\left(R_{i 1}, R_{i 2}, \cdots, R_{i j}\right)=\left(\begin{array}{ccc}
r_{11} & \cdots & r_{1 m} \\
\vdots & \ddots & \vdots \\
r_{j 1} & \cdots & r_{j m}
\end{array}\right)
$$


wherer $_{j m}$ denotes the fuzzy membership of the $j$ th indicator belonging to the mth grade.

Determination of the Fuzzy Evaluation Method. The process of determining the fuzzy evaluation method results consists of the following steps.

The fuzzy evaluation method results of the second-level failure modes are assumed to be

$$
\begin{aligned}
& B_{i}=Q_{i} R_{i}, \\
& Q_{i}=\left(Q_{i 1}, Q_{i 2}, \cdots, Q_{i j}\right),
\end{aligned}
$$

where $\mathrm{Q}_{\mathrm{i}}$ and $\mathrm{Q}_{\mathrm{ij}}$ denote the weight of the second-level failure modes and the weight of the third-level failure modes belonging to the second-level failure modes, respectively.

The fuzzy evaluation method result of the first-level failure mode is assumed to be

$$
\begin{array}{r}
B=Q R, \\
Q=\left(Q_{1}, Q_{2}, \cdots, Q_{n}\right), \\
R=\left(B_{1}, B_{2}, \cdots, B_{n}\right) .
\end{array}
$$

Here, $Q$ and Rindicate the weight of the first-level failure mode and the membership matrix of the first-level failure mode, respectively.

The level parameter method and defuzzification method can be used to obtain the evaluation results of the first-level failure mode more intuitively. The result is assumed to be as follows:

$$
\mathrm{H}=\mathrm{BC}^{\mathrm{T}} \text {. }
$$

\section{FMECA-Fuzzy Evaluation Method}

FMECA is a type of reliability analysis that describes the function of each subsystem, in addition to the fault mode, fault reason, fault rate, and severity level in tabular form. However, FMECA should be improved because the evaluation result is highly abstract. The fuzzy evaluation method can be used to express qualitative results quantitatively, compensating for the deficiencies in FMECA. However, the evaluation results of the fuzzy evaluation method are fuzzy and subjective, and FMECA is necessary to reduce the fuzziness and subjectivity. The FMECA- fuzzy evaluation method can solve a series of problems effectively and render risk assessment results for systems more objective and reasonable. The evaluation process of the FMECA-fuzzy evaluation method is as follows:

Choose the study object and determine the tier-level structure of the object.

Determine the function of each subsystem as well as the failure mode, failure cause, failure rate, and severity level. Score the fault rate and severity level of the fault subsystem. Construct the FMECA table.

Employ the AHP to determine the index weights.

Determine the RPN and determine the RPN levels.

Judge the risk of the subsystem and determine the risk value of the target layer through the fuzzy evaluation method.

\section{Case Study}

In this study, the truss, which is one of the most important parts of a Ferris wheel, was selected as the study object. We analyzed the risk of truss failure through the FMECA-fuzzy evaluation method. The proposed fault system framework of the truss is described in Figure1. 


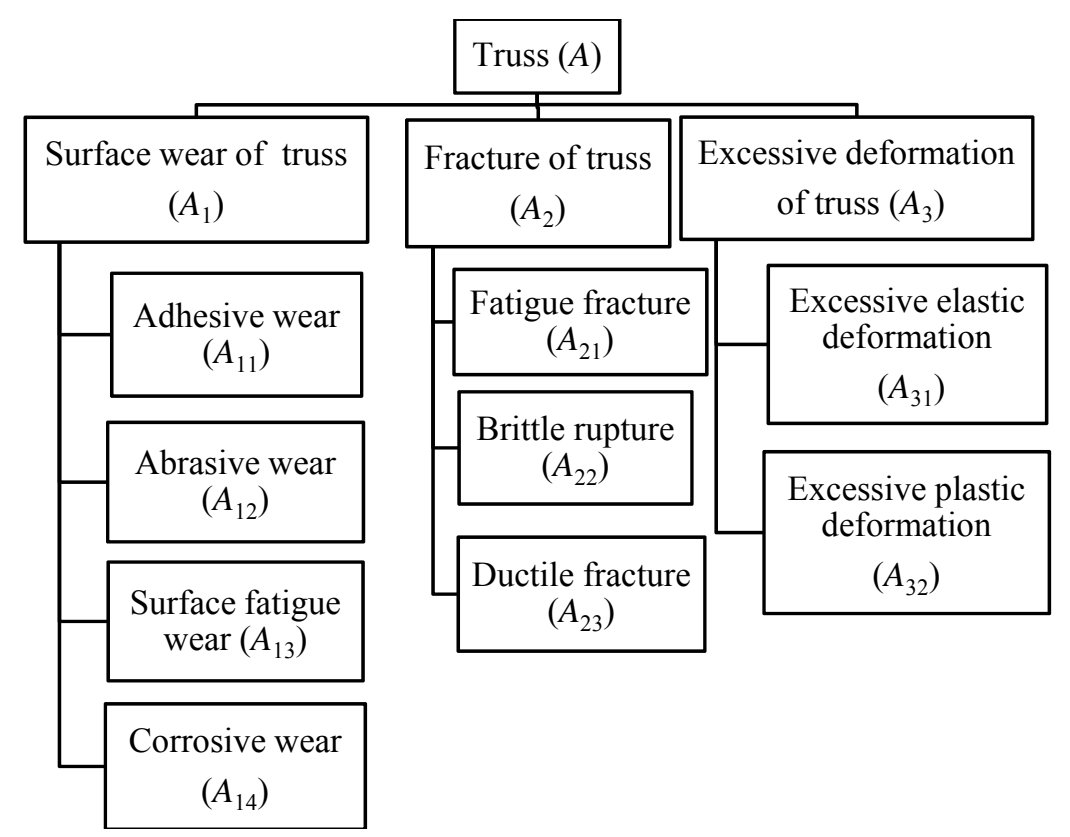

Figure 1. Fault system of truss

Table 5.FMECA-based expert scoring table for the truss

\begin{tabular}{|c|c|c|c|c|c|}
\hline Name & Function & Failure Mode & & $\begin{array}{l}\text { Severity Level of Fault } \\
\text { (Expert Sconing) }\end{array}$ & $\begin{array}{l}\text { Probability } \\
\text { Levelof } \\
\text { Fault } \\
\text { (Expert } \\
\text { Scoring) }\end{array}$ \\
\hline \multirow{8}{*}{ Truss } & \multirow{8}{*}{$\begin{array}{l}\text { Bear axial } \\
\text { tension or } \\
\text { pressure, so as } \\
\text { to make full } \\
\text { use of the } \\
\text { strength of the } \\
\text { material }\end{array}$} & \multirow{3}{*}{$\begin{array}{l}\text { Surface wear of } \\
\text { the truss }\end{array}$} & Adhesive wear & I, II, III,IV, V & $\begin{array}{l}\mathrm{A}, \mathrm{B}, \mathrm{C} \\
\mathrm{D}, \mathrm{E}\end{array}$ \\
\hline & & & $\begin{array}{l}\text { Abrasive wear } \\
\text { Surface fatigue wear }\end{array}$ & $\begin{array}{l}\text { I, II, III, IV, V } \\
\text { I, II, III, IV, V }\end{array}$ & $\begin{array}{l}\text { A, B, C, } \\
\text { D, E } \\
\text { A, B, C, } \\
\text { D, E }\end{array}$ \\
\hline & & & Corrosive wear & I, II, III, IV, V & $\begin{array}{l}\text { A, B, C } \\
\text { D, E }\end{array}$ \\
\hline & & \multirow{3}{*}{$\begin{array}{l}\text { Fracture of the } \\
\text { truss }\end{array}$} & Fatigue fracture & I, II, III, IV, V & $\begin{array}{l}\mathrm{A}, \mathrm{B}, \mathrm{C} \\
\mathrm{D}, \mathrm{E}\end{array}$ \\
\hline & & & Brittle rupture & I, II, III, IV, V & $\begin{array}{l}\mathrm{A}, \mathrm{B}, \mathrm{C} \\
\mathrm{D}, \mathrm{E}\end{array}$ \\
\hline & & & Ductile fracture & I, II, III, IV, V & $\begin{array}{l}\mathrm{A}, \mathrm{B}, \mathrm{C} \\
\mathrm{D}, \mathrm{E}\end{array}$ \\
\hline & & \multirow{2}{*}{$\begin{array}{l}\text { Excessive } \\
\text { deformation of } \\
\text { the truss }\end{array}$} & $\begin{array}{l}\text { Excessive elastic } \\
\text { deformation }\end{array}$ & I, II, III, IV, V & $\begin{array}{l}\mathrm{A}, \mathrm{B}, \mathrm{C} \\
\mathrm{D}, \mathrm{E}\end{array}$ \\
\hline & & & $\begin{array}{l}\text { Excessive plastic } \\
\text { deformation }\end{array}$ & I, II, III, IV, V & $\begin{array}{l}\text { A, B, C } \\
\text { D, E }\end{array}$ \\
\hline
\end{tabular}

FMECA of the Truss. An FMECA expert scoring table was constructed to analyze the function, failure mode, and failure cause of the truss; subsequently, experts scored the ESR and OPR. The FMECA-based expert scoring table of the truss is presented in Table 5 
Determination of the Weight of the Truss. The judgment matrix, weight of the truss, and failure system of the truss are presented in Tables 6-9.

Table 6.Judgment matrix and weight of the truss

\begin{tabular}{lllll}
\hline Importance & $\begin{array}{l}\text { Surface Wear of } \\
\text { the Truss }\end{array}$ & $\begin{array}{l}\text { Fracture of the } \\
\text { Truss }\end{array}$ & $\begin{array}{l}\text { Excessive } \\
\text { Deformation of } \\
\text { the Truss }\end{array}$ & $\begin{array}{l}\text { Weight } \\
\text { Value }\end{array}$ \\
\hline $\begin{array}{l}\text { Surface Wear } \\
\text { of the Truss }\end{array}$ & 1 & $1 / 7$ & $1 / 5$ & 0.4264 \\
$\begin{array}{l}\text { Fracture of the } \\
\text { Truss }\end{array}$ & 7 & 1 & 4 & 0.4234 \\
$\begin{array}{l}\text { Excessive } \\
\begin{array}{l}\text { Deformation of } \\
\text { the Truss }\end{array}\end{array}$ & 5 & $1 / 4$ & 1 & 0.1502 \\
\hline
\end{tabular}

Table 7.Judgment matrix and weight of the surface wear of the truss

\begin{tabular}{llllll}
\hline Importance & Adhesive & Abrasive & Surface & Corrosive & Weight \\
& Wear & Wear & Fatigue Wear & Wear & Value \\
\hline Adhesive Wear & 1 & 1 & 1 & $1 / 3$ & 0.1667 \\
Abrasive Wear & 1 & 1 & 1 & $1 / 3$ & 0.1667 \\
Surface Fatigue & 1 & 1 & 1 & $1 / 3$ & 0.1667 \\
Wear & & & & & \\
Corrosive Wear & 3 & 3 & 3 & 1 & 0.5 \\
\hline
\end{tabular}

Table 8.Judgment matrix and weight of truss fracture

\begin{tabular}{lllll}
\hline Importance & Fatigue Fracture & Brittle Rupture & Ductile Fracture & Weight Value \\
\hline Fatigue Fracture & 1 & $1 / 2$ & $1 / 3$ & 0.1571 \\
Brittle Rupture & 2 & 1 & $1 / 3$ & 0.2493 \\
Ductile Fracture & 3 & 3 & 1 & 0.5936 \\
\hline
\end{tabular}

Table 9.Judgment matrix and weight of excessive deformation of the truss

\begin{tabular}{|c|c|c|c|}
\hline Importance & $\begin{array}{l}\text { Excessive Elastic } \\
\text { Deformation }\end{array}$ & $\begin{array}{l}\text { Excessive Plastic } \\
\text { Deformation }\end{array}$ & $\begin{array}{l}\text { Weight } \\
\text { Value }\end{array}$ \\
\hline $\begin{array}{l}\text { Excessive Elastic } \\
\text { Deformation }\end{array}$ & 1 & $1 / 2$ & 0.3333 \\
\hline $\begin{array}{l}\text { Excessive Plastic } \\
\text { Deformation }\end{array}$ & 2 & 1 & 0.6667 \\
\hline
\end{tabular}

Determination of RPN Levels. The RPN was calculated according to the results of the expert scores in the FMECA table; subsequently, the RPN was divided into five levels, as presented in Table 10.

Table 10.RPN levels

\begin{tabular}{llllll}
\hline RPN & $0-20$ & $21-40$ & $41-60$ & $61-80$ & $81-100$ \\
\hline Level & Very safe & $\begin{array}{l}\text { Relatively } \\
\text { safe }\end{array}$ & Generally safe & $\begin{array}{l}\text { Relatively } \\
\text { dangerous }\end{array}$ & $\begin{array}{l}\text { Very } \\
\text { dangerous }\end{array}$ \\
\hline
\end{tabular}

Fuzzy Evaluation Method of the Second-Level Failure Modes. The first-level failure mode set of truss was assumed to be $A=\left\{A_{1}, A_{2}, A_{3}\right\}=$ \{surface wear of the truss, fracture of the truss, excessive deformation of the truss $\}$. The second-level failure mode sets were assumed to be $A_{1}=$ \{adhesive wear, abrasive wear, surface fatigue wear, corrosive wear $\}, A_{2}=$ \{fatigue fracture, brittle rupture, ductile fracture $\}$, and $A_{3}=$ \{excessive elastic deformation, excessive plastic deformation $\}$. 
In this study, $A_{1}$ was considered as an example, and comprehensive evaluation results of $A_{1}$ were obtained. The comprehensive evaluation process is described as follows:

$A_{1}=\{$ adhesive wear, abrasive wear, surface fatigue wear, corrosive wear $\}$.

$V=\{$ very safe, relatively safe, generally safe, relatively dangerous, very dangerous $\}$.

Statistical results for "adhesive wear" showed that $20 \%$ of the experts received an RPN corresponding to "very safe," and $80 \%$ of the experts acquired an RPN belonging to corresponding to "safe"; therefore, we have $R_{11}=(0.2,0.8,0,0,0)$. Similarly, we have $R_{12}=(0.2,0.8,0,0,0), R_{13}$ $=(0.1,0.9,0,0,0)$, and $R_{14}=(0.1,0.8,0.1,0,0)$. Therefore, the membership matrix of the "surface wear of the truss" can be expressed as

$$
\begin{gathered}
\mathrm{R}_{1}=\left(\begin{array}{ccccc}
0.2 & 0.8 & 0 & 0 & 0 \\
0.2 & 0.8 & 0 & 0 & 0 \\
0.1 & 0.9 & 0 & 0 & 0 \\
0.1 & 0.8 & 0.1 & 0 & 0
\end{array}\right) \\
\mathrm{Q} 1=(0.1667,0.1667,0.1667,0.5), \\
\mathrm{B} 1=\mathrm{Q} 1 \mathrm{R} 1=(0.133,0.817,0.05,0,0), \\
\mathrm{C}=(100,80,60,40,20), \text { and } \mathrm{H} 1=\mathrm{B} 1 \mathrm{CT}=81.66
\end{gathered}
$$

Similarly, we have

$$
\mathrm{R} 2=\left(\begin{array}{ccccc}
0 & 0.4 & 0.5 & 0.1 & 0 \\
0.3 & 0.6 & 0.1 & 0 & 0 \\
0 & 0.2 & 0.5 & 0.3 & 0
\end{array}\right)
$$

$\mathrm{B} 2=\mathrm{Q} 2 \mathrm{R} 2=(0.075,0.331,0.4,0.194,0), \mathrm{H} 2=\mathrm{B} 2 \mathrm{CT}=65.74=65.74(19)$

$$
\mathrm{R} 3=\left(\begin{array}{ccccc}
0.2 & 0.8 & 0 & 0 & 0 \\
0.2 & 0.6 & 0.2 & 0 & 0
\end{array}\right)
$$

$\mathrm{B} 3=\mathrm{Q} 3 \mathrm{R} 3=(0.2,0.667,0.133,0,0), \mathrm{H} 3=\mathrm{B} 3 \mathrm{CT}=81.34 .(21)$

Fuzzy Evaluation Method of the First-Level Failure Mode. We have $A=$ \{surface wear of the truss, fracture of the truss, excessive deformation of the truss $\}$ and $Q=(0.4264,0.4234,0.1502)$. The membership matrix of the first-level failure mode is expressed as

$$
\begin{gathered}
\mathrm{R}=(\mathrm{B} 1, \mathrm{~B} 2, \mathrm{~B} 3)=\left(\begin{array}{ccccc}
0.133 & 0.817 & 0.05 & 0 & 0 \\
0.075 & 0.331 & 0.4 & 0.194 & 0 \\
0.2 & 0.667 & 0.133 & 0 & 0
\end{array}\right) \\
\mathrm{B}=\mathrm{QR}=(0.119,0.589,0.211,0.082,0) \\
\mathrm{C}=(100,80,60,40,20) \\
\mathrm{H}=\mathrm{BCT}=74.96 .
\end{gathered}
$$

From these calculation results, we can conclude that the safety of the truss is high.

\section{Conclusions}

(1)The advantages and disadvantages of the FMECA and fuzzy evaluation methods were analyzed.

(2)The novel FMECA-fuzzy evaluation method proposed in this paper can substantially reduce the fuzziness of evaluation results and express the evaluation results quantitatively. 
(3)The truss of a Ferris wheel was qualitatively and quantitatively analyzed using the proposed FMECA-fuzzy evaluation method. The results show that the safety of the truss was high. The evaluation results may provide a reference value for the design stage and subsequent maintenance stages. They may also provide reference information for relevant departments and personnel for establishing proactive, preventive maintenance procedures.

\section{References}

[1] J.Li, H.B.Xu, Reliability analysis of aircraft equipment based on FMECA method. Physics Procedia.25 (2012) 1816-1822.

[2] N.C.Xiao, H.Z.Huang,Y.F. Li, L.P.He, T.D.Jin, Multiple failure modes analysis and weighted risk priority number evaluation in FMEA, Eng. Fail. Anal. 18 (2011) 1162-1170.

[3] W.Zhang, J.Lu,Y. Zhang, Comprehensive evaluation index system of low carbon road transport based on fuzzy evaluation method, Procedia Eng.137 (2016) 659-668.

[4] M.An, Y.Qin, L.M.Jia, Y.Chen, Aggregation of group fuzzy risk information in the railway risk decision making process, Safety Sci.82 (2016) 18-28.

[5] L.Feng, X.Zhu,X. Sun, Assessing coastal reclamation suitability based on a fuzzy-AHP comprehensive evaluation framework: a case study of Lianyungang, China. Mar. Pollut. Bull.89 (2014) 102-111. 